\title{
Modernización agrícola y valoración sociocultural de los servicios ecosistémicos en paisajes mayas del sureste de México
}

\author{
Yair A. Alpuche-Álvarez ${ }^{1,3} ;$ Susana Ochoa-Gaona, ${ }^{1, \mathbb{D} ;}$ Claudia M. Monzón- \\ Alvarado $^{1 / 4}$ \& Sergio Cortina-Villar ${ }^{2}$ \\ ${ }^{1}$ El Colegio de la Frontera Sur, Unidad Campeche. Departamento de Ciencias de la Sustentabilidad. Grupo Académico \\ Adaptación Humana y Manejo de Recursos en Ecosistemas Tropicales. ${ }^{2}$ El Colegio de la Frontera Sur, Unidad San Cristóbal \\ de las Casas. Departamento de Agricultura, Sociedad y Ambiente. Grupo Académico Estudios Socioambientales y Gestión \\ Territorial. ${ }^{3}$ Centro del Cambio Global y la Sustentabilidad A.C. ${ }^{4}$ Dirección de Cátedras-CONACYT, Consejo Nacional de \\ Ciencia y Tecnología (CONACYT), Ciudad de México, México.
}

Resumen. Proponemos una estrategia de tres etapas para evaluar el impacto de la mecanización de la agricultura en la valoración sociocultural de paisajes con agricultura tradicional de milpa. El método consistió en la aplicación de entrevistas semi-estructuradas a 60 pobladores de dos comunidades mayas con diferente historia de mecanización de la agricultura. En cada entrevista se recopiló información general de los encuestados, además de las tres técnicas de valoración de servicios ecosistémicos: listado libre, una matriz de evaluación y la ordenación de preferencias de unidades del paisaje. Los resultados muestran que la valoración sociocultural de los servicios ecosistémicos en ambas comunidades es muy similar. Las comunidades comparten el $58 \%$ de los servicios ecosistémicos listados. Ambas comunidades reconocen el carácter multifuncional del bosque; sin embargo, en la priorización de unidades del paisaje destacan las unidades que proveen de alimentos: las milpas en la comunidad tradicional y las unidades de agricultura mecanizada en la comunidad modernizada. Esta diferencia se explica por el ingreso económico asociado a la venta de excedentes en la agricultura mecanizada. En conclusión, la modernización agrícola no tuvo un impacto importante en la valoración sociocultural de servicios ecosistémicos, pero sí en la jerarquía de las unidades del paisaje. Además, se reconoce la relevancia local de cada unidad del paisaje en la provisión de servicios relevantes para el modo de vida de los mayas, lo que explica la persistencia de estos paisajes heterogéneos y multifuncionales.

[Palabras clave: métodos mixtos, métodos participativos, paisajes rurales, factores de cambio, milpa, mecanización, agricultura tradicional]

\begin{abstract}
Aвstract. Agricultural modernization and socio-cultural valuation of ecosystem services in Mayan landscapes of southeastern Mexico. The impact of modernization on the sociocultural valuation of ecosystem services in rural landscapes has been little studied. We propose a three-step strategy to evaluate the impact of agricultural mechanization on the sociocultural valuation of landscapes with traditional milpa agriculture. The method entailed the application of semi-structured interviews to 60 settlers from two Mayan communities with different agriculture's mechanization history. Each interview included general information collection of the respondents as well as three ecosystem services valuation techniques: a free listing, an assessment matrix, and the ranking of the landscape units. These instruments were applied to 60 participants in two Mayan communities differentiated by 30 years from the beginning of agriculture mechanization. The results highlight a similar valuation of ecosystem services in both communities. Communities share $58 \%$ of the landscape services listed. Participants in both communities recognize the multifunctional character of the forest. Nevertheless, greater importance was assigned to food provisioning areas: milpa in the traditional community and to mechanized lands in the modernized community. This most significant difference found between communities is explained by the economic income associated with the sale of surpluses in mechanized agriculture. In conclusion, agricultural modernization has not had an important impact on the sociocultural valuation of ecosystem services, but in the importance of the landscape units. In addition, we capture the local recognition of each unit on the provision services relevant for the Mayan way of life, which explains the persistence of these heterogeneous and multifunctional landscapes.
\end{abstract}

[Keywords: mixed methods, participatory methods, rural landscapes, drivers of change, milpa, mechanization, traditional agriculture]

Editora asociada: Ana Cingolani
Recibido: 11 de Diciembre de 2017

Aceptado: 16 de Enero de 2019 


\section{INTRODUCCIÓN}

La modernización del campo mexicano promovida por la revolución verde en los años sesenta incentivó el uso de maquinaria y de agroquímicos para producir cultivos (Gómez de Silva 2001; Herrera Tapia 2013). A través de este proceso aumentó la productividad agrícola mediante monocultivos, con un aumento parcial de los ingresos económicos (Herrera Tapia 2013). No obstante, también trajo asociadas consecuencias ambientales negativas como la pérdida de biodiversidad, la contaminación de cuerpos agua y la deforestación, entre las más importantes (Turner 1989; Horrigan et al. 2002). La evaluación de los impactos generados por la modernización de la agricultura en las dimensiones económica y ambiental presenta resultados divergentes. Sin embargo, los cambios que la modernización agrícola generó en los procesos asociados a la dimensión social, en particular a los atributos socioculturales (e.g., valores, creencias, conocimientos tradicionales, entre otros), no se han abordado con la misma intensidad.

La dimensión sociocultural del valor de los servicios que brindan los ecosistemas se evalúa a través de las creencias y las prácticas, de los valores atribuidos y de la relación sociedad-naturaleza. Lockwood (1999) denomina valores atribuidos a "los valores que las personas asignan a las cosas, ya sea que sean bienes como la madera, actividades como la recreación o servicios como la educación". Estos valores también corresponden a los servicios que perciben las personas de los ecosistemas conocidos como servicios ecosistémicos (SE). La modernización puede modificar o transformar los atributos socioculturales mediante el proceso de aculturación (Krotz 1997). Los cambios en las percepciones de las personas pueden impactar de manera negativa sobre los paisajes culturales, ya que la condición de los recursos naturales inmersos en estos sistemas se asocia a las formas de apropiación material y simbólica de los mismos (Morales-Jasso 2016). En este sentido, la modernización promueve la revalorización social del entorno, lo que modifica la manera en que se toman las decisiones sobre la ordenación espacial de los ecosistemas dentro del territorio; esto afecta la dinámica de los procesos ecológicos.

El marco conceptual de los servicios ecosistémicos fue propuesto a principios del siglo XXI para reconocer el papel que desempeñan los ecosistemas en el bienestar humano (Bieling et al. 2014; Plieninger et al. 2014). Se clasifica como SE a cualquier beneficio tangible e intangible que derive de los ecosistemas y agrosistemas (deGrootetal.2002; Haines-Young and Potschin 2010; Wiggering et al. 2016). De forma complementaria, a estos sistemas se los puede valorar de manera biofísica, económica y sociocultural (MartínLópez et al. 2014). La dimensión biofísica mide los servicios ecosistémicos mediante indicadores ecológicos (ver Burkhard et al. 2014), mientras que la dimensión económica se encarga de atribuir valores monetarios a los servicios ecosistémicos (Cristeche and Penna 2008). La valoración sociocultural se centra en el estudio de los SE al considerar la opinión de los múltiples actores sociales que pueden aprovechar los beneficios de los paisajes y los ecosistemas inmersos en ellos (Bieling et al. 2014; Iniesta-Arandia et al. 2014; LópezSantiago et al. 2014; Scholte et al. 2015; Schmidt et al. 2017). En esta valoración sociocultural se evalúan las percepciones, perspectivas, valores y opiniones que los habitantes tienen sobre el paisaje en el que viven. Algunas estrategias para conocer el valor sociocultural de los servicios ecosistémicos incluyen usar imágenes, listados, entrevistas o mapeos, entre otros. Los estudios que involucran la dimensión sociocultural se han desarrollado en menor medida que los estudios biofísicos y económicos (Balvanera et al. 2009).

Nuestra hipótesis es que la aculturación que promueve la modernización agrícola también puede afectar la relación sociedadnaturaleza en términos de la valoración sociocultural de los servicios que brindan los ecosistemas y los agrosistemas. Una aproximación para evaluar este supuesto es la cascada de servicios ecosistémicos propuesta por Haines-Young y Potschin (2010). Este modelo sostiene que la estructura del paisaje condiciona los procesos ecológicos que derivan en servicios ecosistémicos que, al ser aprovechados por las personas, les dan valor económico, biofísico y sociocultural (Müller et al. 2010; Kandziora et al. 2013; Burkhard et al. 2014). De esta manera se explica una reacción en cadena entre los componentes de este modelo. Esto quiere decir que los cambios en la estructura del paisaje, propiciados por factores como la modernización agrícola, pueden transformar la valoración económica, biofísica y sociocultural. Este trabajo se centra en la dimensión sociocultural del valor de los servicios ecosistémicos. Para 
poner a prueba este modelo, se planteó como pregunta de investigación: ¿En qué medida la modernización agrícola modificó la valoración sociocultural de los servicios ecosistémicos aprovechados por los mayas? Se incluyeron tres preguntas particulares: 1) ¿Se perciben los mismos servicios ecosistémicos en comunidades con diferente historia de modernización agrícola? 2) En comunidades con diferente historia de modernización agrícola, ¿se asocian las mismas unidades del paisaje a los mismos servicios ecosistémicos? y 3) En comunidades con diferente historia de modernización agrícola, ¿se otorga el mismo orden de importancia a las unidades de los paisajes?

\section{MATERIALES y MÉTODOS}

\section{Área de estudio}

La península de Yucatán está conformada por los estados mexicanos de Campeche, Quintana Roo y Yucatán. Está habitada por el grupo cultural de los mayas yucatecos. Este grupo indígena es el segundo más grande de México después del Náhuatl. En su mayoría, los mayas viven en zonas rurales dedicadas a la agricultura tradicional y presentan un grado de marginación elevado. El tipo de agricultura que los mayas practican recibe el nombre de milpa de roza debido al proceso de roza-tumba y quema. Este proceso consiste en un ciclo agrícola con períodos de descanso en los cuales se corta y derriba la vegetación natural con hacha y machete, y luego se quema y labra a mano con algunas herramientas de construcción artesanal (Granados-Sánchez et al. 1999). Los espacios agrícolas resultantes, llamados milpas, son policultivos en los que predominan el maíz (Zea mays), el frijol (Phaseolus spp.) y la calabaza de semilla (Cucurbita spp.), además de hortalizas como chayote (Sechium edule), yuca (Manihot esculenta) y chaya (Cnidoscolus chayamansa). Toledo et al. (2008) señalan que en los territorios mayas se combina el ciclo agrícola de la milpa con otras unidades como los huertos familiares o solares. En los solares se cultiva gran variedad de hortalizas y frutales, además de tener animales de traspatio: gallinas, pollos, pavos y cerdos. No obstante, con las políticas productivistas de modernización de finales del siglo XX se introdujo la agricultura mecanizada que implica la renta o compra de maquinaria para el labrado de la tierra e insumos agroquímicos como fertilizantes y plaguicidas para el monocultivo de maíces híbridos. En el estado de Campeche, las tierras de agricultura mecanizada se trabajan considerando la estacionalidad de las lluvias, ya que la infraestructura hídrica es casi inexistente debido a la ausencia de cuerpos de agua superficial y a la profundidad de los mantos freáticos.

El municipio de Hopelchén se ubica el este del estado de Campeche. Se lo considera un territorio con potencial agrícola (Uzcanga Pérez et al. 2012). Es por este potencial que los menonitas, un grupo cultural extranjero, favorecido por el gobierno estatal se asentó en algunas zonas del territorio municipal. Los agricultores menonitas tienen gran capacidad económica y cuentan con maquinaria para producir monocultivos. En este sentido, Ellis et al. (2017) les atribuye a estas prácticas agrícolas gran parte de las tasas elevadas de deforestación en el municipio. Porter-Bolland et al. (2008) también señalan que en la zona se realizaron actividades madereras y de extracción de látex para la producción de chicle.

El tipo de clima es cálido sub-húmedo, con lluvias en verano. En un $90 \%$ de la extensión territorial, la vegetación dominante es bosque tropical húmedo en diferentes estadios sucesionales (Gómez de Silva 2001; Ellis et al. 2017). El relieve se caracteriza por lomeríos que no exceden los 250 m s. n. m. (KAIROS 2007; INEGI 2010). Los terrenos con pendiente están dispersos por todo el territorio, por lo que no existen grandes extensiones de planicies. El municipio se divide en dos regiones: una, al norte, denominada "La milpa", caracterizada por tener mayor aptitud para las actividades agrícolas, y otra descrita como tradicional porque predomina la agricultura de milpa conocida como "La montaña" (Porter-Bolland et al. 2008). En "La montaña", la agricultura mecanizada no había sido reportada en publicaciones previas al 2010. Cabe señalar que la referencia "montaña" es una denominación local que se emplea porque en esta región se encuentran los lomeríos de mayor altitud.

Los mayas habitan en comunidades a las que la reforma agraria mexicana les dotó tierra. Las dotaciones, llamadas ejidos, constituyen territorios cuyo uso depende de las decisiones tomadas por una asamblea conformada por ejidatarios (Ley Agraria 2017). Los ejidatarios son principalmente hombres con derechos legales de uso de la tierra. Los hombres que no cuentan con derechos agrarios, pero trabajan una porción de tierra se conocen 
como comuneros o avecindados. Los jóvenes y mujeres constituyen el resto de la población y se autodenominan pobladores.

En sus diferentes niveles, el gobierno mexicano se encarga de otorgar subsidios a través de diferentes programas a las áreas rurales del país, incluyendo los ejidos del municipio de Hopelchén. El Programa de Apoyos Directos al Campo (Procampo) tiene por objetivo "complementar el ingreso económico de los productores del campo mexicano, ya sean de autoconsumo o de abastecimiento, para contribuir a su crecimiento económico individual y al del país en su conjunto" (https://tinyurl.com/ yy589to5). Los apoyos de este programa son otorgados por la Secretaría de Agricultura, Ganadería, Desarrollo Rural, Pesca y Alimentación (SAGARPA). La SAGARPA brinda otro apoyo, generalmente de insumos e infraestructura a las comunidades, denominado PESA o Proyecto Estratégico de Seguridad Alimentaria, cuyo objetivo principal es "Apoyar a las unidades de producción familiar en localidades rurales de alta y muy alta marginación, para mejorar su capacidad productiva"(http:/ / bit.do/eQjLm). Ambos programas tienen fines productivos aplicables a espacios como los huertos familiares (solares) o las tierras agrícolas mecanizadas (mecanizados). El programa de pagos por servicios ambientales (PSA) es responsabilidad de la Comisión Nacional Forestal (https: / / tinyurl.com/4psnmn7) y la misma financia la conservación de distintos tipos de vegetación del país.

\section{Caracterización de las comunidades}

La escasez de información documental disponible para elaborar este estudio requirió obtener datos de base para comparar las comunidades. Se eligió el municipio de Hopelchén en Campeche porque allí existen dos regiones impactadas diferencialmente por la modernización de la agricultura. Se consideró el ejido como la unidad de análisis por ser la unidad territorial donde los mayas toman decisiones sobre la ordenación de los ecosistemas y agrosistemas (e.g., la vegetación natural, la agricultura, la ganadería, etc.). El manejo de los territorios genera los patrones espaciales que conforman los paisajes característicos de ambas regiones. Para la selección de los ejidos se tomó en cuenta el tamaño del área productiva del ejido y el tamaño de la población. Para conocer la organización y el manejo del territorio se realizaron entrevistas semi-estructuradas a los representantes de los ejidos. Se utilizó la información documental sobre el modelo de uso múltiple del territorio propuesto en Barrera-Bassols y Toledo (2005) y Toledo (2008) como una guía para clasificar los ejidos en unidades de provisión de servicios ecosistémicos. Además, para corroborar la clasificación se hicieron recorridos de campo con habitantes de las comunidades. Luego se utilizaron imágenes de Google Earth para realizar el mapeo de las unidades de paisaje (UP). Como unidades de paisaje se entienden los sub-sistemas socio-ecológicos de los cuales las personas obtienen diferentes bienes y servicios. Se utilizó una perspectiva etnoecológica para generar una clasificación comprensible para los entrevistados de las comunidades.

\section{Valoración sociocultural de los servicios ecosistémicos}

Para valorar socioculturalmente los servicios ecosistémicos se aplicaron entrevistas semiestructuradas al $10 \%$ de la población de ambos ejidos. En total se entrevistaron 30 personas por ejido. El siguiente criterio de elección fue el género, por lo que en cada ejido se entrevistaron 15 hombres y 15 mujeres. Finalmente, se procuró que los entrevistados representaran a la población joven, de edad media y de edad avanzada. Otro aspecto fundamental fue que la persona entrevistada tuviera la intención de participar y que no existieran barreras de lenguaje. Por ejemplo, algunos pobladores de la región de la montaña no hablaban español, por lo que fueron excluidas de las entrevistas. La primera parte de la entrevista recopiló información general de los entrevistados para complementar la descripción de los ejidos seleccionados: edad, sexo, ocupación. Posteriormente, se pusieron en práctica las tres técnicas de valoración. La entrevista se encuentra anexa como información complementaria. El estudio aborda la pregunta de investigación desde una perspectiva socio-ecológica a través de métodos mixtos, mediante el uso de estadística no paramétrica y métodos etnográficos. Dado que las dos comunidades comparten un bagaje cultural y que enfrentan condiciones ecológicas y sociopolíticas distintas, el estudio de las percepciones no ofrece una independencia real de las muestras, pero sí permite observar variaciones en las percepciones colectivas. Por otra parte, debido a la baja disponibilidad de 
los miembros de la comunidad para participar en las entrevistas no fue factible hacer repeticiones por comunidad para robustecer la investigación (Hulbert 1984).

Con el objetivo de realizar la valoración se utilizó la información obtenida de la clasificación de unidades del paisaje (UP). Una vez que las UP fueron identificadas se buscaron fotografías que las personas entrevistadas pudieran reconocer con facilidad. Las fotografías se pusieron en una planilla y se mostraron a todos los participantes antes de iniciar con las técnicas de valoración. A cada persona se le preguntó si podía reconocer cada una de las fotografías. Una vez que los entrevistados habían respondido esta pregunta se procedió a la entrevista.

\section{Listado libre}

El listado libre ofree-listing es una técnica que consiste en elaborar una pregunta abierta que permita realizar una lista con todas aquellas cosas que los entrevistados consideren importantes (en este caso, los ecosistemas) (Fagerholm et al. 2016). La pregunta utilizada fue: ¿Qué cosas buenas, importantes, útiles o valiosas obtiene dentro de su ejido por parte de los sitios que le he mostrado en la planilla? Para generar un listado de servicios ecosistémicos desde la perspectiva de los actores locales, las respuestas se clasificaron según la semántica. Los resultados se analizaron utilizando los indicadores de riqueza (cantidad de servicios), abundancia (porcentaje de entrevistados que mencionaron cada servicio), diversidad (índice de Shannon-Wiener) (Plieninger et al. 2013; Vreese et al. 2016; Angarita-Baez et al. 2017) y similitud (índice de Jaccard). Las formulas se pueden encontrar en la información complementaria.

\section{Matriz de evaluación}

La matriz de evaluación se elaboró con base en la propuesta de Burkhard et al. (2014). Consiste en colocar en las filas de una matriz los servicios ecosistémicos que se desean evaluar y en las columnas las unidades de paisaje. Las casillas se llenan con valores entre el 0 y 5, que representan la capacidad de los ecosistemas para proveer de determinados servicios ecosistémicos. Adaptamos la técnica para realizar una valoración sociocultural, considerando que los habitantes de los paisajes son los expertos locales sobre los bienes y servicios que brindan las unidades que componen los paisajes (Paudyal et al. 2015; Burkhard et al. 2015).

Durante cada entrevista semi-estructurada se utilizó un formato (ver Anexo en la Información Complementaria) para llenar la matriz. En el formato se enlistaron 25 servicios ecosistémicos mencionados con frecuencia en la literatura. A estos se añadieron dos servicios asociados a la dimensión económica (ingresos económicos y el empleo). Esto se debió a: 1) la libertad de la dimensión sociocultural para asignar valores a los paisajes (Lockwood 1999; Scholte et al. 2015) y 2) la probabilidad de encontrar aspectos económicos en las respuestas de los entrevistados. En la entrevista se hicieron 27 preguntas, una por cada servicio listado, parafraseando cada servicio ecosistémico para conocer cuáles son esas unidades del paisaje que los proveen. Por ejemplo, para el caso de la regulación del clima local se les preguntó: ¿Cuál o cuáles de los sitios que están en la planilla de fotos hacen que el clima esté fresco o agradable? Después, las personas respondían los nombres de las unidades del paisaje que, según su opinión, les brindaban el servicio y se apuntaban en el formato. Todas las respuestas por comunidad se volcaron en la matriz de evaluación, contando la cantidad de entrevistados (frecuencia) que mencionaron que un servicio era brindado por una unidad de paisaje. Bajo este criterio se consideró que un servicio enlistado por más personas para una UP en particular representa un servicio de mayor importancia en términos de la valoración sociocultural, ya que es un servicio que está más presente en el conocimiento de los mayas y que, además, se reconoce a una UP como importante para la provisión de tal servicio. Las frecuencias se compararon entre las matrices (comunidad tradicional vs. comunidad modernizada) mediante una prueba de chi-cuadrado. En total se compararon 189 pares de casillas. Luego, para simular el método de Burkhard et al. (2014) se generaron intervalos de importancia con base en las frecuencias. Las ponderaciones se expresaron como: $5=25 \mathrm{a}$ 30 respondientes, muy alta importancia; $4=$ 19 a 24, alta importancia, $3=13$ a 18, mediana importancia; $2=7$ a 12, baja importancia; $1=$ 1 a 6, muy baja importancia. En caso de que ninguna persona mencionara la provisión, se consideró sin importancia (0). Esto señala, a nivel de comunidad, cuán importante es cada UP, según los entrevistados, en cuanto a la provisión de servicios ecosistémicos. 
Ordenamiento de unidades de paisaje

El ordenamiento de unidades es una técnica que permite conocer las preferencias de las personas sobre una unidad del paisaje. Consistió en solicitar a los participantes que organizaran las imágenes de las siete unidades del paisaje de mayor a menor importancia. Para ello se imprimieron las fotografías de las UP y se elaboraron tarjetas que ellos pudieran acomodar sobre alguna superficie. Sobre esta base se le otorgó un valor a cada posición. La primera posición se consideró como la más importante y recibió el valor máximo de 7 puntos debido a que ese es el número de UP involucradas. La última posición corresponde a la unidad de menor importancia y que recibió un valor de 1 . Se calcularon los promedios de respuesta para cada UP para asignar la posición que representa a nivel de comunidad. Adicionalmente, se calculó la desviación estándar para los valores de cada UP. Para analizar los resultados de la ordenación de preferencias se aplicó la prueba no paramétrica de U Mann-Whitney para datos ordinales y se compararon los valores obtenidos entre la comunidad modernizada y la tradicional.

\section{RESUltados}

\section{Descripción de las comunidades}

Las comunidades de las dos regiones consideradas dentro del municipio de Hopelchén comparten características culturales, aunque también presentaron diferencias. La mayoría de las personas indígenas sólo estudian la educación básica o primaria que llega hasta la edad de 12 años. Después, los hombres y mujeres se incorporan a las actividades agrícolas. Los hombres trabajan en el campo, se dedican a las labores en la milpa o agricultura tradicional (MI) y las tierras de agricultura mecanizada denominadas localmente como mecanizados (ME). Estos mecanizados son trabajados mediante la renta de maquinaria a los grupos de menonitas que viven cerca de los ejidos. Los mayas les pagan a los menonitas por la labranza de la tierra, pero la siembra y el control de plagas lo hacen de forma manual. Ninguna de las comunidades cuenta con sistemas de riego. Las mujeres, en cambio, se dedican a las labores del hogar y al cuidado del huerto familiar. Localmente se le llama solar (SO) a todo el espacio que incorpora el huerto y la casa. En ambas comunidades se reciben los programas Procampo, PESA y Pago por Servicios Ambientales (PSA).

En el ciclo de cultivo de la milpa se desmonta y cultiva un espacio de bosque por un período de tres años. Después se deja crecer la vegetación secundaria (VS) para recuperar el suelo. Algunos terrenos con vegetación secundaria se usan para ganadería, se encierran con cercos rudimentarios y se siembran porciones de pasto junto con la vegetación secundaria que crece. A estas unidades se les conoce como potreros (PO). Los bajos inundables (BA) o aguadas están presentes en las dos comunidades mayas. Son espacios de vegetación natural con suelos de baja permeabilidad que se inundan durante la temporada de lluvias. En estos espacios también crecen pastos nativos de la región. La mayor proporción del territorio de los ejidos está constituida por los bosques (BO), que es la vegetación madura o en estadios avanzados de la sucesión vegetal. Las dos comunidades consideradas son: "Chunyaxnik", ubicada en la región de "La Milpa" y que nosotros denominamos como "comunidad modernizada", y "Pachuitz" que denominamos como "comunidad tradicional" ubicada en la región de "La montaña" (Figura 1).

La agricultura mecanizada se realiza en las planicies, mientras que los bosques se mantienen en las colinas con pendientes pronunciadas. Las milpas pueden trabajarse en lugares planos poco pedregosos, aunque lo más frecuente es que se ubiquen en pendientes con poca inclinación. La vegetación secundaria crece en espacios donde se ha abandonado la agricultura de milpa o un potrero. Los potreros pueden estar en pendientes o en planadas dependiendo de la disponibilidad de terreno. Los bajos inundables se distribuyen de manera aleatoria en el espacio, ya que su existencia está asociada al tipo de suelo. Finalmente, los solares se condensan a manera de parches. El conjunto de solares sumado a la infraestructura (i.e., iglesias, comisarías, tiendas de conveniencia) conforman el "poblado". En total se determinaron siete unidades de paisaje (Figura 1, Tabla 1): bosques (BO), bajos inundables (BA), vegetación secundaria (VS), potreros (PO), milpas (MI), solares (SO) y mecanizados (ME).

\section{Comunidad modernizada-Chunyaxnik}

Este sitio se ubica a sólo una hora de la capital del municipio de Hopelchén. La población del 

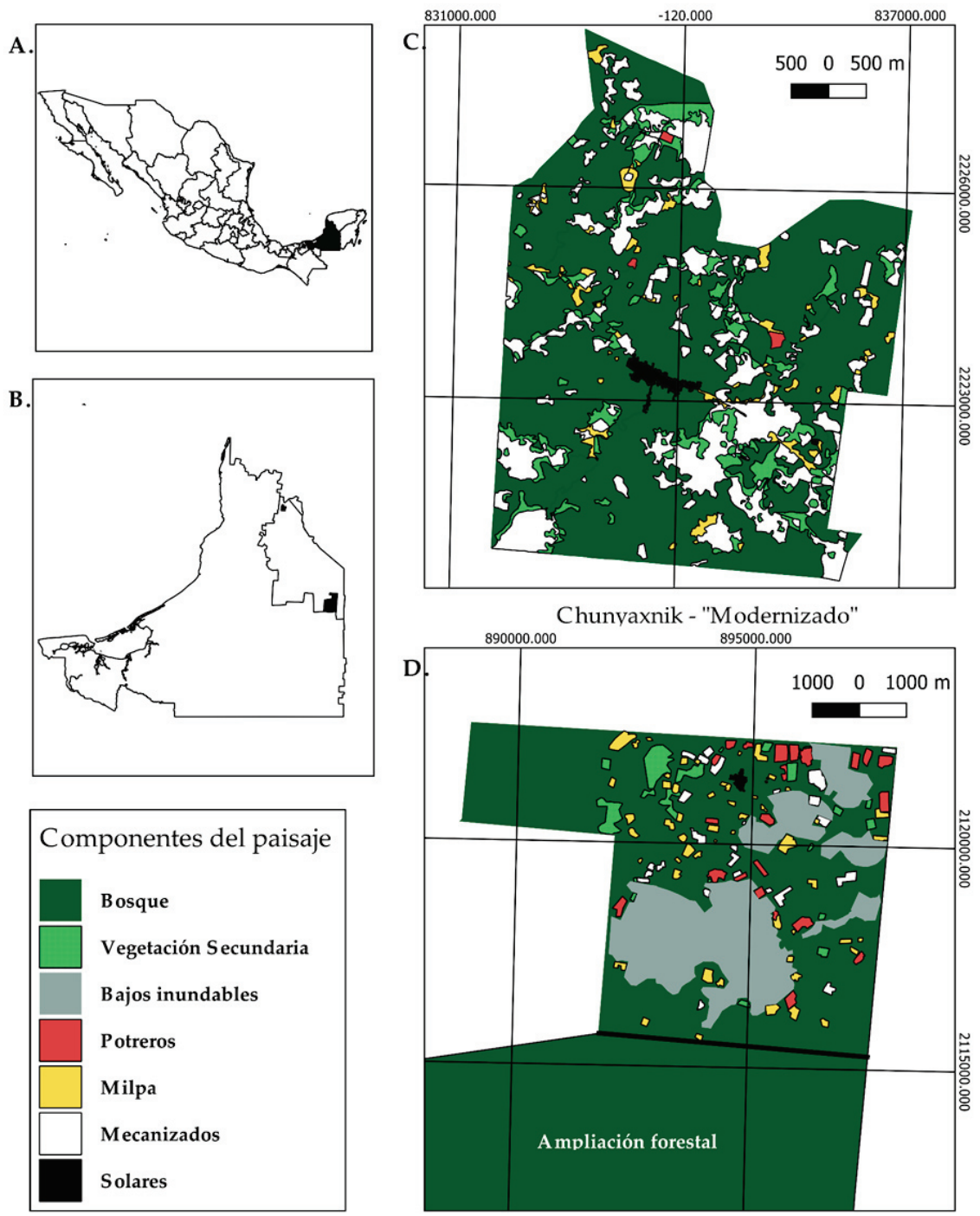

\begin{tabular}{|l|l|}
\hline Componentes del paisaje \\
Bosque \\
Vegetación Secundaria \\
Bajos inundables \\
Potreros \\
\hline$\square$ Milpa \\
\hline$\square$ Mecanizados \\
\hline$\square$ Solares
\end{tabular}

Pachuitz - "Tradicional"

Figura 1. Ubicación de los ejidos y configuración de las unidades del paisaje. A) Ubicación del estado de Campeche. B) Ubicación del municipio de Hopelchén y los ejidos considerados. C) Distribución de las unidades del paisaje en el ejido Chunyaxnik (modernizado). D) Distribución de las unidades del paisaje en el ejido Pachuitz (tradicional).

Figure 1. Location of the communities and landscape components. A) Location of the state of Campeche. B) Location of the municipality of Hopelchén and the ejidos considered. C) Distribution of landscape units in the Chunyaxnik ejido (modernized). D) Distribution of landscape units in the Pachuitz ejido (traditional).

ejido de Chunyaxnik es poco mayor que la de la comunidad tradicional (Tabla 1). Los núcleos familiares son más pequeños, es decir, el padre, la madre y los hijos. Existen algunas cooperaciones entre hijos y padres para el trabajo agrícola. La distribución de los solares en el pueblo muestra un mayor grado de individualización ya que existen cercos que delimitan las propiedades. Cuentan con el programa de pago por servicios ambientales dentro del área productiva del ejido (Tabla 1). La gente mayor de esta comunidad se comunica en español. Incluso los ancianos hablan un español claro, aunque también entienden la lengua maya. Los niños y jóvenes no conocen la lengua indígena, por lo que sólo hablan español. Los mecanizados se expandieron por todos los terrenos planos del ejido; los remanentes de bosque se mantienen en las colinas. La superficie de mecanizados es diez veces mayor que la de milpas (Figura 1, Tabla 1). Los bosques se usan para el programa de pago por servicios ambientales; también tienen permiso para extraer leña y materiales de construcción. La vegetación secundaria se encuentra principalmente en la parte basal de los cerros o en sitios con uso agrícola previo. Las aguadas (i.e., cuerpos de agua asociados a 
Tabla 1. Comparación de los dos ejidos estudiados. *Unidades del paisaje cuya proporción fue significativamente diferente.

Table 1. Comparison of the two studied communities. *Landscape units whose proportion was significantly different.

\begin{tabular}{llcc}
\hline & & Modernizada & Tradicional \\
\hline Características & Población (habitantes) & 364 & 266 \\
generales & Programa de pago por servicios & Sí & Sí \\
& ambientales (Comisión Nacional Forestal) & & \\
& Otros apoyos gubernamentales & PROCAMPO/PESA// & PROCAMPO/PESA/PROGAN \\
& Actividad agrícola principal & ProGAN & \\
& & Producción de maíz en & Producción de maíz, frijol y \\
& Inicio de la mecanización (año aprox.) & 1980 & calabaza en milpa tradicional \\
Unidades del & Área total de aprovechamiento & 2898 & 2010 \\
paisaje (ha) & Área total del ejido & 2898 & 4821 \\
& Total forestal & 1988 & 24000 \\
& Superficie forestal de aprovechamiento & 1988 & 22428 \\
& Superficie de la ampliación forestal & 0 & 3164 \\
& *Mecanizado (ME) & 553 & 19264 \\
& *Bajos inundables (BA) & 0 & 92 \\
& Vegetación secundaria (VS) & 234 & 1167 \\
& Potreros (PO) & 6 & 137 \\
& Milpas (MI) & 84 & 117 \\
& Solar (SO) & 20 & 136 \\
\hline
\end{tabular}

los bajos inundables) son muy pequeñas como para verlas a la escala del mapa de la Figura 1 y quedaron rodeadas por la agricultura mecanizada. Actualmente, se encuentran secas por el aumento de la temperatura que genera la ausencia de vegetación arbórea. La actividad pecuaria es escasa ya que es una actividad que no les parece redituable. Practican la agricultura de temporal y cuentan con agua entubada en el área de solares.

\section{Comunidad tradicional-Pachuitz}

Este ejido se ubica a poco más de dos horas de la capital del municipio. La comunidad del ejido Pachuitz presenta escasez hídrica debido a la profundidad de los mantos acuíferos. Hasta el año del presente estudio recibían frecuentemente ayuda del gobierno municipal, que les suministraba agua a través de camiones distribuidores. La lengua maya se usa de manera cotidiana; el español lo emplean sólo con visitantes o en casos particulares de algunos inmigrantes que no hablan la lengua local. Las familias trabajan de manera cooperativa entre padres, madres, hijos, hermanos y primos. La propiedad corresponde a la familia nuclear, pero el trabajo y algunos espacios (e.g., silos y corrales) son compartidos. Los mecanizados y milpas se encuentran en proporciones similares y están dispersos por toda el área de aprovechamiento, por lo que se observan como pequeños parches dentro del territorio (Figura 1). En términos del paisaje, el bosque conforma una gran matriz que envuelve pequeños parches de otras unidades de paisaje. Cabe mencionar que en esta comunidad los bajos inundables ocupan grandes áreas. Además, este ejido cuenta con una ampliación forestal otorgada por el gobierno del Estado. Estas ampliaciones son extensiones de tierra que les concesionaron a los ejidos para conservar la vegetación, por lo que no tienen permisos para cambiar el uso de suelo. No obstante, pueden realizar actividades como la cacería no comercial de algunas especies y gestionar el programa de pagos por servicios ambientales. La vegetación de los bajos inundables no está incluida en este programa. Los potreros son grandes debido a la disponibilidad de espacio y a que el tipo de suelo permite que crezcan pastos de alto valor nutritivo para el ganado. La vegetación secundaria corresponde a espacios de abandono de la milpa. El área ocupada por los solares es menor que en la comunidad modernizada (Tabla 1). Reciben el programa de pagos por servicios ambientales por $\sim 3000$ ha de bosque que se encuentra en la ampliación forestal. Aunque toda la ampliación (19000 ha) está bajo conservación, no todo el bosque cumple con los criterios de la CONAFOR porque el programa sólo apoya hasta cierta cantidad de hectáreas ya que depende de fondos federales. 
Tabla 2. Categorización de los servicios ecosistémicos mencionados en el listado de respuesta abierta. El porcentaje de entrevistados corresponde a la cantidad de personas por comunidad que mencionaron cada servicio en su listado. *Servicios ecosistémicos que mostraron diferencias estadísticas entre comunidades.

Table 2. Categorization of the ecosystem services mentioned in the free-listing. The percentage of respondents corresponds to the number of people per community who mentioned each service in their list. *Ecosystem services that showed statistical differences between communities.

\begin{tabular}{|c|c|c|c|c|}
\hline & Beneficio & $\begin{array}{c}\% \text { de } \\
\text { entrevistados } \\
\text { (modernizada) }\end{array}$ & $\begin{array}{c}\% \text { de } \\
\text { entrevistados } \\
\text { (tradicional) }\end{array}$ & Descripción \\
\hline & Producción de maíz & 83.3 & 66.7 & Capacidad de la tierra para producir maíz \\
\hline & $\begin{array}{l}\text { Almacenamiento-suministro } \\
\text { de agua }\end{array}$ & 66.7 & 66.7 & $\begin{array}{l}\text { Capacidad del paisaje para almacenar- } \\
\text { suministrar agua }\end{array}$ \\
\hline & $\begin{array}{l}\text { Capacidad para proveer } \\
\text { múltiples cultivos }\end{array}$ & 60 & 60 & $\begin{array}{l}\text { Capacidad de producir diferentes especies de } \\
\text { plantas con base a las preferencias familiares }\end{array}$ \\
\hline & Producción animal & 46.7 & 63.3 & $\begin{array}{l}\text { Capacidad del paisaje para mantener animales } \\
\text { domésticos con fines alimenticios }\end{array}$ \\
\hline & ${ }^{*}$ Generación de viento & 36.7 & 13.3 & $\begin{array}{l}\text { Capacidad del paisaje para regular las corrientes } \\
\text { de aire }\end{array}$ \\
\hline & Soporte a la apicultura & 26.7 & 16.7 & $\begin{array}{l}\text { Capacidad del paisaje para proveer de recursos } \\
\text { necesarios para la apicultura }\end{array}$ \\
\hline & $\begin{array}{l}\text { Capacidad para el } \\
\text { establecimiento de milpas }\end{array}$ & 26.7 & 33.3 & $\begin{array}{l}\text { Potencial del paisaje para establecer milpas de } \\
\text { espeque }\end{array}$ \\
\hline & Hábitat para la biodiversidad & 26.7 & 16.7 & $\begin{array}{l}\text { Potencial del paisaje para fungir como hábitat de } \\
\text { múltiples especies }\end{array}$ \\
\hline & $\begin{array}{l}\text { Capacidad para producir sin } \\
\text { fertilizantes }\end{array}$ & 13.3 & 10 & $\begin{array}{l}\text { Capacidad del paisaje para producir alimentos } \\
\text { sin usar fertilizantes }\end{array}$ \\
\hline$\stackrel{\mathscr{D}}{\Xi}$ & $\begin{array}{l}\text { Capacidad de proveer ingresos } \\
\text { económicos }\end{array}$ & 13.3 & 16.7 & $\begin{array}{l}\text { Capacidad del paisaje para aportar con los } \\
\text { ingresos monetarios }\end{array}$ \\
\hline 宓 & $\begin{array}{l}\text { Capacidad de recuperación de } \\
\text { la vegetación }\end{array}$ & 10 & 10 & $\begin{array}{l}\text { Capacidad de paisaje para dar lugar a la sucesión } \\
\text { secundaria de la vegetación }\end{array}$ \\
\hline $\begin{array}{l}\overrightarrow{7} \\
\text { के } \\
0\end{array}$ & $\begin{array}{l}\text { Reducción del calentamiento } \\
\text { global }\end{array}$ & 3.3 & 6.7 & $\begin{array}{l}\text { Capacidad del paisaje para reducir el } \\
\text { calentamiento global }\end{array}$ \\
\hline$\stackrel{0}{0}$ & `Producción de oxígeno & 3.3 & 33.3 & Capacidad del paisaje para producir oxígeno \\
\hline$\frac{\pi}{\tilde{D}}$ & *Soporte de la ganadería & 3.3 & 30 & $\begin{array}{l}\text { Capacidad del paisaje para proveer recursos para } \\
\text { la ganadería }\end{array}$ \\
\hline$\ddot{\ddot{Z}}$ & Soporte a la provisión de lluvia & 3.3 & 13.3 & $\begin{array}{l}\text { Capacidad del paisaje para contribuir con la } \\
\text { generación de lluvia }\end{array}$ \\
\hline & $\begin{array}{l}\text { Potencial de uso para } \\
\text { programas gubernamentales }\end{array}$ & 3.3 & - & $\begin{array}{l}\text { Capacidad de la tierra para establecer insumos } \\
\text { e infraestructura provista por programas }\end{array}$ \\
\hline & $\begin{array}{l}\text { Provisión de materiales de } \\
\text { construcción }\end{array}$ & 3.3 & - & $\begin{array}{l}\text { gubernamentales } \\
\text { Capacidad del paisaje para proveer materiales } \\
\text { útiles en la construcción de casa y herramientas }\end{array}$ \\
\hline & Regulación de la erosión & 3.3 & - & Capacidad del paisaje para mitigar la erosión \\
\hline & Producción frutícola & - & 40 & $\begin{array}{l}\text { Capacidad del paisaje para producir con árboles } \\
\text { frutales }\end{array}$ \\
\hline & Almacenamiento de carbono & - & 6.7 & Capacidad del paisaje para almacenar $\mathrm{CO}_{2}$ \\
\hline & Aprovisionamiento de sombra & - & 6.7 & Capacidad del paisaje para bloquear la luz solar \\
\hline & Drenaje de agua & - & 3.3 & $\begin{array}{l}\text { Capacidad del paisaje para permitir el flujo y } \\
\text { absorción en suelo del agua }\end{array}$ \\
\hline & Protección ante huracanes & - & 3.3 & $\begin{array}{l}\text { Capacidad del paisaje para mitigar los impactos } \\
\text { de huracanes }\end{array}$ \\
\hline
\end{tabular}

\section{Listado de respuesta libre}

En total se registraron 36 servicios, de los cuales 21 se compartieron entre las dos comunidades mayas (Tabla 2). A algunos de los valores o servicios enlistados no se los considera servicios ecosistémicos, pero se los incluyó en los resultados para su posterior discusión. Los SE con más menciones por los entrevistados correspondieron a los enfocados a atender necesidades básicas: la producción de maíz, el almacenamiento-suministro de agua, la capacidad para proveer de múltiples cultivos y la producción de animales. Otros beneficios no directamente vinculados con la alimentación fueron el sentimiento de hogar, la reducción de costos, el aprecio de la naturaleza y el sentimiento de bienestar. En la comunidad modernizada se encontró una riqueza de 29 servicios. En esta comunidad se reconoció el sentido de propiedad ( $26.7 \%$ de los entrevistados), la estética (13.3\%), la reducción del esfuerzo del trabajo $(6.7 \%)$ y la provisión de plantas ornamentales (6.7\%). Por su parte, en la comunidad tradicional se encontraron 28 servicios ecosistémicos; algunos no 
compartidos como la producción frutícola $(40 \%)$, la seguridad personal en la producción agrícola $(20 \%)$, almacenamiento de carbono $(6.7 \%)$ y el aprovisionamiento de sombra $(6.7 \%)$ (Tabla 2). Los índices de diversidad fueron casi equivalentes, con valores de 2.9 y 3.0 en la comunidad modernizada y en la tradicional, respectivamente. En cuanto al índice de Jaccard, se encontró una similitud intermedia entre los servicios identificados por cada comunidad (0.58).

\section{Matriz de evaluación}

Con base en los resultados de las 189 comparaciones, $21(\sim 10 \%)$ mostraron diferencias significativas en las pruebas de chi-cuadrada. En comparación con la comunidad tradicional, en la comunidad mecanizada más personas asociaron los bosques con los servicios de drenaje hídrico y hábitat para la fauna. Los mecanizados se asociaron a servicios de corredores biológicos, recreación, cultural-religioso, educacional, empleo e ingresos económicos. Las milpas se asociaron a los servicios de recreación y empleo. La vegetación secundaria se asoció a hábitat para la flora. Los solares, a servicios como drenaje hídrico y la producción de plantas ornamentales. Por su parte, la belleza escénica y los bajos inundables se asociaron a la protección contra huracanes. En cambio, en la comunidad tradicional, más personas

Tabla 3. Comparación de las matrices de evaluación sociocultural. Unidad del paisaje: $\mathrm{BO}=$ bosque, BA=bajos inundables, $\mathrm{VS}=$ vegetación secundaria, $\mathrm{PO}=$ potreros, $\mathrm{MI}=$ milpas, $\mathrm{SO}=$ solares, $\mathrm{ME}=$ mecanizados. Las categorías corresponden a los rangos de entrevistados que asociaron los servicios con las unidades de paisaje. 0 ( 0 entrevistados $)=\sin$ importancia, 1 (1-6 entrevistados)=importancia muy baja, 2 (7-12 entrevistados)=importancia baja, 3 (13-18 entrevistados)=imp ortancia media, 4 (19-24 entrevistados)=importancia alta, 5 (25-30 entrevistados)=importancia muy alta. *Valores cuya comparación entre ejidos mostró diferencias significativas. En verde de mayor importancia, en rojo de menor importancia.

Table 3. Matrix comparison of sociocultural assessment. Landscape unit: $\mathrm{BO}=$ forest, $\mathrm{BA}=$ flooding lands, $\mathrm{VS}=$ secondary vegetation, $\mathrm{PO}=$ grasslands, $\mathrm{MI}=$ traditional maize crop, $\mathrm{SO}=$ home garden, $\mathrm{ME}=$ mechanized lands. The categories correspond to the ranges of respondents who associated the services with the landscape units. $0(0$ interviewed $)=$ unimp ortant, 1 (1-6 interviewed)=very low importance, 2 (7-12 interviewed $)=$ low importance, 3 (13-18 interviewed)=medium importance, 4 (19-24 interviewed)=high importance, 5 (25-30 interviewed)=very high importance. *Values whose comparison between ejidos showed significant differences. In green higher importance, in red minor importance

\begin{tabular}{|c|c|c|c|c|c|c|c|c|c|c|c|c|c|c|}
\hline \multirow[t]{2}{*}{ Servicios ecosistémicos } & \multicolumn{7}{|c|}{ Modernizada } & \multicolumn{7}{|c|}{ Tradicional } \\
\hline & $\mathrm{BO}$ & BA & VS & $\mathrm{PO}$ & MI & $\mathrm{SO}$ & ME & $\mathrm{BO}$ & BA & VS & $\mathrm{PO}$ & MI & $\mathrm{SO}$ & ME \\
\hline Provisión de aire limpio & 4 & 1 & 1 & 0 & 1 & 1 & 1 & 4 & 1 & 1 & 1 & 1 & 1 & 1 \\
\hline Regulación del clima local & 4 & 1 & 1 & 1 & 1 & 1 & 1 & 4 & 2 & 1 & 0 & 0 & 0 & 1 \\
\hline Protección contra huracanes & 3 & $1^{*}$ & 1 & 0 & 0 & $0^{*}$ & 0 & 3 & $0^{*}$ & 1 & 0 & 0 & $1^{*}$ & 0 \\
\hline Drenaje hídrico & $2^{*}$ & $3^{*}$ & 1 & 1 & 1 & $1^{*}$ & 1 & $1^{*}$ & $4^{*}$ & 0 & 0 & 0 & $0^{*}$ & 0 \\
\hline Almacenamiento de agua & 1 & 3 & 1 & 0 & 0 & 1 & 0 & 0 & 4 & 0 & 1 & 0 & 1 & 0 \\
\hline Fertilidad del suelo & $1^{*}$ & 1 & 1 & 1 & 1 & 1 & 1 & $2^{*}$ & 1 & 1 & 1 & 1 & 1 & 1 \\
\hline Control del ruido & 2 & 1 & 1 & 1 & 1 & 1 & 1 & 2 & 0 & 1 & 0 & 0 & 1 & 0 \\
\hline Polinización & 4 & 1 & 1 & 1 & 1 & 1 & 1 & 3 & 1 & 1 & 1 & 1 & 1 & 0 \\
\hline Control de plagas & 1 & 0 & 1 & 0 & 0 & 0 & 0 & 2 & 0 & 1 & 0 & 1 & 1 & 0 \\
\hline Corredores & 4 & $1^{*}$ & 1 & 1 & 2 & 0 & $2^{*}$ & 4 & $2^{*}$ & 1 & 1 & 1 & 1 & $1^{*}$ \\
\hline Hábitat de fauna & $5^{*}$ & 1 & 1 & 0 & 1 & 0 & 1 & $4^{*}$ & 1 & 1 & 1 & 1 & 0 & 1 \\
\hline Áreas de reproducción & 5 & 1 & 1 & 0 & 0 & 0 & 0 & 4 & 1 & 1 & 1 & 0 & 1 & 0 \\
\hline Hábitat de flora & 4 & 1 & $2^{*}$ & 1 & 1 & 1 & 1 & 3 & 1 & $1^{*}$ & 1 & 1 & 1 & 1 \\
\hline Cacería & 4 & 1 & 1 & 1 & 1 & 1 & 1 & 4 & 1 & 1 & 1 & 2 & 1 & 1 \\
\hline Fibras & 2 & 0 & 1 & 1 & 1 & 1 & 1 & 3 & 1 & 1 & 1 & 1 & 1 & 0 \\
\hline Desarrollo de animales domésticos & 1 & 1 & 1 & 3 & 1 & 4 & 1 & 1 & 1 & 1 & 2 & 1 & 3 & 1 \\
\hline Materiales de construcción & 5 & 1 & 1 & 1 & 1 & 1 & 1 & 4 & 1 & 1 & 0 & 0 & 1 & 0 \\
\hline Plantas medicinales & 4 & 0 & 1 & 0 & 0 & $1^{*}$ & 0 & 4 & 1 & 1 & 1 & 1 & $1^{*}$ & 1 \\
\hline Producción de cultivos & 0 & 0 & 0 & 0 & 4 & 2 & 4 & 0 & 0 & 0 & 0 & 5 & 3 & 4 \\
\hline Producción de plantas ornamentales & 1 & 1 & 1 & 1 & 1 & 3 & 1 & 3 & 1 & 1 & 0 & 0 & 2 & 0 \\
\hline Belleza escénica & 3 & 2 & 2 & 1 & 1 & $4^{*}$ & 2 & 5 & 2 & 1 & 2 & 2 & $2^{*}$ & 2 \\
\hline Recreación & $1^{*}$ & 3 & 1 & 1 & $2^{*}$ & 1 & $2^{*}$ & $3^{*}$ & 2 & 0 & 1 & $1^{*}$ & 0 & $1^{*}$ \\
\hline Inspiracional & 2 & 2 & 1 & 1 & 1 & 1 & 1 & 2 & 1 & 1 & 1 & 1 & 1 & 1 \\
\hline Cultural-Religioso & 3 & 1 & 1 & 1 & 2 & 2 & $2^{*}$ & 1 & 1 & 1 & 1 & 1 & 2 & $1^{*}$ \\
\hline Educacional & 3 & 1 & 1 & 2 & 2 & 1 & $2^{*}$ & 3 & 1 & 1 & 1 & 1 & 1 & $1^{*}$ \\
\hline Empleo & 1 & 1 & 1 & $1^{*}$ & $3^{*}$ & 1 & $4^{*}$ & 1 & 1 & 1 & $2^{*}$ & $1^{*}$ & 1 & $3^{*}$ \\
\hline Ingreso económico & 1 & 0 & 1 & 1 & 2 & 1 & $5^{*}$ & 2 & 0 & 0 & 2 & 1 & 1 & $2^{*}$ \\
\hline
\end{tabular}


asociaron al bosque a los servicios de fertilidad del suelo y la recreación; los solares, a la protección contra huracanes; los bajos inundables, al drenaje hídrico y corredores biológicos, y los potreros se asociaron a la provisión de empleo. De las 21 diferencias, seis se atribuyeron a los mecanizados, cuatro a los solares y bosques, tres a los bajos, dos a las milpas y, uno a vegetación secundaria y potreros (Tabla 3).

En ambas comunidades se identificaron a los bosques como los proveedores de mayor cantidad de servicios ecosistémicos. El resto de las casillas de ambas matrices (>90\%) fueron ocupadas por valores de nula a mediana importancia (Tabla 3). Sólo 8\% y 6\% de las casillas, de las comunidades modernizada y tradicional, respectivamente, se llenaron con valores de alta (valores 4) y muy alta importancia (valores 5). En los casos de muy alta importancia, la comunidad modernizada reconoció 4 servicios con este valor, mientras que la comunidad tradicional sólo 1. Respecto a los valores de alta importancia, la comunidad modernizada reconoció 12 servicios y la comunidad tradicional, 11. El bosque es asociado de manera importante (valores 4 y 5) a los servicios de provisión de aire limpio, regulación del clima local, polinización, corredores, hábitat para la fauna, áreas de reproducción, hábitat para la flora, cacería, materiales de construcción, belleza escénica y plantas medicinales. Las milpas se relacionaron a la producción de cultivos; los solares a la producción de animales y la belleza escénica (únicamente en la comunidad modernizada), y los bajos, al drenaje y almacenamiento de agua (únicamente comunidad tradicional). Sólo en la comunidad modernizada los mecanizados fueron importantes en la provisión de ingresos económicos y empleos.

\section{Ordenación de unidades de paisaje}

Se identificó que los actores locales ordenan las unidades según el tipo de beneficio que obtienen de ellos. Para la comunidad modernizada, el elemento con mayor relevancia es el mecanizado. Por su parte, en la comunidad tradicional, la milpa fue la unidad con mayor importancia. En ambos casos, las unidades productivas ocuparon los primeros lugares (mecanizados, milpas y solares) (Tabla 4). El bosque fue colocado en cuarto y quinto lugar de importancia, según la comunidad modernizada y tradicional. La vegetación secundaria fue ubicada en último lugar de importancia. La comparación estadística con la prueba de U-Mann Whitney sólo mostró diferencias significativas entre la manera que las comunidades valoran la importancia de los mecanizados y los bajos. Para la comunidad tradicional, los bajos fueron más importantes que en la comunidad modernizada. En cambio, la comunidad modernizada le dio más importancia a los mecanizados que la comunidad tradicional.

Tabla 4. Ordenación de las unidades del paisaje según su importancia en la provisión de servicios ecosistémicos. Los valores subrayados reflejan el promedio de las preferencias a nivel comunitario. El valor máximo posible es 7 , ya que es el valor más alto posible dentro de la ordenación de unidades de paisaje. Las unidades del paisaje marcadas con un asterisco mostraron diferencias significativas en la prueba de U-Mann Whitney.

Table 4. Landscape units ranked according the importance to producers in the provision of ecosystem services. The underlined values reflect the average of preferences at the community level. The Landscape units marked with an asterisk showed significant differences in the U-Mann Whitney test.

\begin{tabular}{|c|c|c|c|c|c|c|}
\hline \multicolumn{7}{|c|}{ Ordenación de componentes del paisaje } \\
\hline \multicolumn{3}{|c|}{ Modernizada } & \multirow[b]{2}{*}{ Posición } & \multicolumn{3}{|c|}{ Tradicional } \\
\hline Componente & $\begin{array}{c}\text { Desviación } \\
\text { estándar }\end{array}$ & Promedio & & Promedio & $\begin{array}{c}\text { Desviación } \\
\text { estándar }\end{array}$ & Componente \\
\hline Mecanizado* & 2.06 & 5.7 & & 4.73 & 1.69 & Milpa \\
\hline Solares & 2.09 & 4.97 & & 4.67 & 2.07 & Solares \\
\hline Milpa & 1.41 & 4.5 & & 4.47 & 1.82 & Bajos* \\
\hline Bosque & 2.12 & 3.87 & & 4.27 & 1.7 & Mecanizado* \\
\hline Potreros & 1.61 & 3.7 & & 3.97 & 2.01 & Bosque \\
\hline Bajos* & 1.77 & 3.47 & & 3.27 & 2.05 & Potreros \\
\hline $\begin{array}{l}\text { Vegetación } \\
\text { secundaria }\end{array}$ & 1.86 & 3.47 & & 3.23 & 1.84 & $\begin{array}{l}\text { Vegetación } \\
\text { secundaria }\end{array}$ \\
\hline
\end{tabular}




\section{DISCUSIÓN}

\section{Similitudes en la valoración sociocultural de servicios ecosistémicos}

Las comunidades mostraron una gran cantidad de similitudes en su valoración de servicios ecosistémicos. En el listado de ambas comunidades se destacaron los beneficios involucrados en la supervivencia de las personas y los que mantienen sus medios de vida. Los beneficios asociados a la producción de alimentos fueron los más mencionados (Tabla 2 y Tabla 3). Además, existen otros beneficios de carácter psicológico que fueron reconocidos en ambas comunidades, como el sentimiento de hogar, la realización personal por el empleo, el aprecio por la naturaleza o la capacidad para cultivar maíces nativos. Algunos de estos servicios enlistados no corresponden a la tipología común, pues tienen un carácter contextualizado. Estos servicios se pueden asociar a servicios culturales según la Evaluación de los Ecosistemas del Milenio (2005) o a la función de información según de Groot (2002). Con base en las pruebas de chi-cuadrado aplicadas para las matrices de evaluación, las comunidades son $90 \%$ similares en la asociación unidad del paisaje-servicio. El análisis de las matrices mostró que las unidades más importantes en la provisión de servicios, para ambos sitios, son los bosques, los mecanizados, las milpas y los solares. La valoración sociocultural de servicios ecosistémicos y de las fuentes de provisión de servicios reveló que en ambas comunidades se tiene una estrecha relación en la forma de ver el mundo, pese el desfase del impacto de las políticas públicas. Por esta razón, es difícil argumentar que la modernización agrícola por sí sola haya generado transformaciones importantes en la cultura de grupos de ascendencia milenaria.

Los resultados de la ordenación de unidades del paisaje mostraron que los solares ocupan el segundo puesto de importancia para ambas comunidades. La razón principal por la cual las comunidades ubican a los solares como una unidad del paisaje valiosa es por su capacidad de proveer cultivos y alimentos proteicos (Tabla 3), que son útiles y diversos para la alimentación (Barrera-Bassols and Toledo 2005; Toledo et al. 2008; Pérez Izquierdo et al. 2012; Galhena et al. 2013; Cahuich-Campos et al. 2014). En ellos, las familias establecen animales de traspatio, frutales y otros productos alimenticios. Se entiende que ambas comunidades valoren de manera importante esta unidad de paisaje por ser fundamental para la asegurar sus medios de vida. Por su parte, milpas o mecanizados son las unidades de los paisajes más relevantes, ambas como unidades primordiales para obtener el cultivo base de la cultura maya: el maíz.

Sin importar el tiempo de modernización o el impacto sobre la estructura del paisaje, ambas comunidades asocian los mismos valores a los ecosistemas y agrosistemas inmersos. La similitud en la valoración de los servicios ecosistémicos en comunidades mayas demuestra cierta resistencia cultural que pudiera vincularse a la importancia que tiene cada beneficio que provee el paisaje en términos biológicos y socioculturales. Esta resistencia la atribuimos a lo que se conoce como núcleo duro (Corona 2010). El núcleo duro de un grupo cultural se refiere a aquellas características unificadoras que son más arraigadas y difíciles de modificar por eventos externos. Otra de las razones para hallar esta gran cantidad de similitudes es la complejidad de los sistemas socio-ecológicos. La teoría de la complejidad establece que existen procesos organizados jerárquicamente que ocurren a corto, mediano y largo plazo (Holling 2001). Los cambios culturales de los valores ocurren a escalas de tiempo mayores que los cambios en las decisiones de los grupos sociales. Por esta razón, la diferenciación de las comunidades no es notoria, puesto que un período de 30 años podría no ser adecuado para encontrar diferencias destacables.

\section{Diferencias en la valoración sociocultural de servicios ecosistémicos}

Se asume que las diferencias más relevantes encontradas en la valoración de servicios ecosistémicos se atribuyen al cambio de prioridades de las unidades de producción. En la agricultura tradicional, la milpa es el espacio de mayor valor cultural ya que es la única forma de obtención de alimentos en la que se produce el maíz y otros cultivos asociados. Con la modernización agrícola, los mecanizados se convirtieron en la principal fuente de maíz y, actualmente, es donde la mayoría de los hombres invierten su tiempo. En la comparación con las unidades de producción agrícola, según la prueba estadística aplicada en las matrices de valuación, seis casos mostraron que los mecanizados fueron más valorados en la comunidad modernizada: la importancia 
de los mecanizados como corredores, como espacios de recreación, como espacios de valor religioso-cultural, como espacios de educación, de empleo y como espacios para la generación de ingresos económicos (Tabla 3). Estas percepciones sobre la importancia del mecanizado en la provisión de servicios ecosistémicos se deben a factores contextuales. Por ejemplo, la mayor área ocupada por los mecanizados en el ejido de la comunidad modernizada genera mayor visibilidad de especies silvestres, ya que para cruzar los parches de bosque los animales deben desplazarse a través de los mecanizados. En las unidades de agricultura mecanizada, la fauna silvestre puede encontrar alimento, por lo que es normal que visiten estos sitios. Además, los mecanizados (ME) representan espacios de educación, ya que los jóvenes deben aprender cómo labrar, fertilizar y mantener los cultivos; de recreación, porque las familias enteras participan en la cosecha y eso forma parte de sus actividades de recreo; y culturalesreligiosos, porque ahora los rituales para pedir por buena cosecha se llevan a cabo no sólo en la milpa, sino en el mecanizado. Finalmente, debido a la capacidad de los ME para producir más cantidad de maíz por unidad de espacio a comparación de la milpa, se convirtieron en fuentes de productos comerciales. Por ello, en la matriz resaltan los servicios de generación de ingresos monetarios y de empleo. Ambos tienen en común el flujo económico.

En la Tabla 1 y en Figura 1 se observa que las principales diferencias en el paisaje ocurren debido a la relación milpa-mecanizado. En la comunidad más tradicional, ambos sistemas se encuentran en la misma proporción; primero, porque los mecanizados tienen menor tiempo de integración en el territorio; segundo, porque en el territorio de la comunidad tradicional la pendiente y la heterogeneidad edáfica entre suelos inundables y pedregosos complican la tarea de encontrar espacios aptos para producir de forma mecanizada. Las proporciones milpa-mecanizado en la comunidad modernizada muestran una diferenciación en la importancia de los mecanizados. Los mecanizados se extendieron para ocupar las planicies, pero las milpas no desaparecieron de los territorios. Esto se constata al comparar la cantidad de milpas presentes en ambas comunidades.

En la literatura, los dos sistemas de producción se diferencian por su dinámica productiva. Las milpas proveen mayor variedad de cultivos, generalmente, maíz, frijol y calabaza. Schmook et al. (2013) y Mardero et al. (2015) señalan que la milpa o agricultura tradicional presenta evidentes ventajas ante procesos como la globalización y el cambio climático. Las personas pueden producir mayor variedad de productos para llevar al mercado o para la alimentación; además las especies cultivadas están adaptadas a las características ambientales de la región. La existencia de la milpa también implica la conservación de la vegetación secundaria. Las milpas se establecen en espacios donde la sucesión vegetal permitió la recuperación del suelo, lo que les confiere una mayor productividad natural de bajo costo. En cambio, los mecanizados se dedican sólo a la producción intensiva de maíces híbridos (Gómez de Silva 2001). Es decir, son cultivos monoespecíficos. El mantenimiento es prácticamente dependiente del ser humano. Los ME implican la fertilización del suelo debido al desgaste y al uso continuo de la tierra. Para optimizar la producción se practican monocultivos, por lo que el sistema no genera relaciones ecológicas complejas como en el caso de la milpa. El monocultivo conlleva el uso de plaguicidas y las consecuentes resistencias a estos por parte de las plagas. La inversión es mayor puesto que los insumos deben ser comprados.

\section{El papel del uso múltiple maya en la valoración sociocultural de la multifuncionalidad de los paisajes}

Mantener el bienestar de las familias requiere que el paisaje tenga la capacidad de proveer múltiples servicios ecosistémicos (multifuncionalidad). Con base en lo explicado por Opdam (2013), los mayas - como otros grupos culturales - valoran los paisajes por los beneficios que pueden obtener de ellos. La multifuncionalidad depende de la heterogeneidad del paisaje (Brandt 2003). Por esta razón, los mayas utilizan el modelo de uso múltiple explicado por Toledo et al. (2008): pueden satisfacer sus necesidades biológicas y socioculturales. Aunque los paisajes sean fisonómicamente distintos, la valoración sociocultural, sugiere que su multifuncionalidad se mantiene. Los mayas lograron incorporar las unidades de agricultura mecanizada a su sistema de uso múltiple, por lo que no transformaron su cosmovisión o sus prácticas, sino que las expandieron al incorporar nuevas unidades de paisaje como los potreros y mecanizados. 
En el modelo de uso múltiple - con los mecanizados y potreros añadidos-, cada una de las unidades de paisaje es relevante para desempeñar funciones particulares. El bosque es la UP con mayor multifuncionalidad al ser considerado con una mayor capacidad de proveer servicios culturales, de regulación y de aprovisionamiento (Tabla 3). Esto concuerda con las expectativas derivadas de la literatura sobre la multifuncionalidad de los bosques, por ejemplo en Führer (2000) y Campos et al. (2005). Además, ello indica que las comunidades son capaces de evaluar bienes intangibles como algunos servicios culturales y de regulación, como se observó en otras evaluaciones de la valoración sociocultural (Bieling et al. 2014; Fagerholm et al. 2016). La vegetación secundaria (VS), también provee servicios útiles para el modo de vida de los mayas. En el listado, 10\% de los entrevistados de las comunidades reconocieron como un beneficio la capacidad para la regeneración de la vegetación, debido a la recuperación de la fertilidad del suelo durante el período de descanso entre la milpa y el bosque como unidad agrícola. Además, la diversidad de especies melíferas de la vegetación secundaria contribuye a las actividades agrícolas mediante el soporte a la apicultura. En Ayala Arcipreste (2001) se encuentran listadas algunas especies melíferas utilizadas en la península de Yucatán: Gymnopodium floribundum (dzidzilché), Piscidia piscipula (jabín) y Caesalpinia gaumeri (kitim che'), entre otras.

La milpa y el mecanizado son unidades que cambiaron su importancia en la comunidad con mayor tiempo de modernización. Sin embargo, los resultados muestran que son complementarias. Ambas contribuyen en la producción de maíz. Sin embargo, el maíz que se utiliza en los mecanizados representa una fuente mayor de producto por menor esfuerzo, aunque con mayor inversión monetaria y costo ecológico. Este producto, además, contribuye con la economía campesina, pues una proporción de la producción de maíz se comercializa y representa una fuente de ingresos. Esta unidad del paisaje se adaptó al modelo tradicional de uso múltiple que permite la inclusión de los mayas en una economía más globalizada y la obtención de bienes que no se producen en el territorio, como la fruta, la tecnología y la indumentaria. En cambio, el maíz de las milpas tiene un valor cultural; representa el trabajo de los ancestros y la resistencia ante la variabilidad ambiental propia de la región, ya que son variedades de maíz adaptadas por coevolución. Cabe mencionar que la producción de maíces nativos puede significar bajos costos de producción (Altieri 2004), por lo que puede ser incluida en el modelo sin competir con aquella de los mecanizados en las decisiones de los agricultores. Conservar las milpas y sus servicios implica conservar la vegetación secundaria (Saenz-Pedroza 2015). Los mecanizados, milpas y solares son unidades importantes del paisaje para los servicios de aprovisionamiento. Estas unidades se destacaron en la provisión de cultivos, mientras que los solares también contribuyen en la producción de animales domésticos. Representan la alimentación de las comunidades mayas y la base de su supervivencia. Los potreros contribuyen como fuente de ahorro económico durante épocas de escasez del recurso monetario. Mientras tanto, los bajos inundables son fuente de recursos hídricos en ausencia de agua potable, en particular en la comunidad tradicional. Esto se observa en la Figura 1 y en el listado libre, donde resalta la capacidad del paisaje para almacenar agua.

En el aspecto metodológico, pese a las limitaciones estadísticas a las que se enfrenta la investigación, consideramos que el ejercicio se robustecería con una mayor cantidad de repeticiones por comunidad. Sin embargo, creemos que los resultados seguirían siendo los mismos. Lo anterior, debido a la cohesión cultural de las comunidades donde la información (conocimientos y percepciones derivadas de los mismos) se transmite de forma similar entre los habitantes. Los ejidos estudiados tampoco representan muestras verdaderas ya que, aunque se ubican espacialmente separadas, pertenecen al mismo grupo cultural. Por esta razón no representan muestras independientes. Tampoco resultaba viable abordar este aspecto, ya que para que esto ocurriera se debería haber considerado una metodología distinta (e.g., abordar la pregunta desde dos grupos culturales distintos).

\section{CONCLUSIONES}

Con base en los resultados del presente trabajo se concluyó que la modernización agrícola tuvo poco impacto sobre la valoración sociocultural de los servicios ecosistémicos provistos en paisajes mayas. En general, las comunidades utilizan los mismos servicios ecosistémicos y reconocen 
las mismas fuentes provisoras de servicios ecosistémicos. La mayor diferencia está en la importancia que les confieren a las unidades del paisaje. Es decir, existe un cambio en las prioridades de los mayas respecto de los mecanizados. La multifuncionalidad de los paisajes también se asocia a la heterogeneidad de los ecosistemas y agrosistemas inmersos en el paisaje, que es mantenida por ambas comunidades en composición a través del modelo de uso múltiple del territorio. Si bien manejan las mismas siete UP, difieren en las proporciones que ocupa cada una y el arreglo espacial. Pese a los cambios estructurales del paisaje y la inserción de nuevas prácticas, las comunidades aprovechan, desde su valoración sociocultural, una riqueza similar de servicios ecosistémicos.

Agradecimientos. Con especial atención se agradece a los habitantes de las comunidades, en particular a las personas que respondieron las entrevistas por permitir el acercamiento a su cultura y el acceso sus territorios. Al Consejo Nacional de Ciencia y Tecnología de México por el apoyo financiero a través de la beca de posgrado número 597671 y al Colegio de la Frontera Sur por el apoyo para el uso de la infraestructura y las facilidades institucionales para el desarrollo de esta investigación.

\section{REFERENCIAS}

Altieri, M. A. 2004. Linking ecologists and traditional farmers in the search for sustainable agriculture. Frontiers in Ecology and the Environment 2:35-42. https://doi.org/10.1890/1540-9295(2004)002[0035:LEATFI]2.0.CO;2.

Angarita-Baez, J. A., E. Pérez-Miñana, J. E. B. Vargas, C. A. R. Agudelo, A. P. Ortiz, E. Palacios, and S. Willcock. 2017. Assessing and mapping cultural ecosystem services at community level in the Colombian Amazon. International Journal of Biodiversity Science, Ecosystem Services and Management 13:280-296. https://doi.org/10.1080/ 21513732.2017.1345981.

Ayala Arcipreste, M. E. 2001. La apicultura en la península de Yucatán: Un acercamiento desde la ecología humana. Tesis de Maestría. Centro de Investigación y de Estudios Avanzados del I.P.N., Unidad Mérida, Yucatán, México.

Balvanera, P., H. Cotler, O. Aburto-Oropeza, A. C. Abigail, A. P. Martha, M. Aluja, A. C. Adolfo, and I. ArroyoQuiroz. 2009. Estado y tendencias de los servicios ecosistémicos. Pp. 185-245. Capital Natural de México. México D.F., México.

Barrera-Bassols, N., and V. M. Toledo. 2005. Ethnoecology of the Yucatec Maya: Symbolism, Knowledge and Management of Natural Resources. Journal of Latin American Geography 4:9-41. https:/ /doi.org/10.1353/lag.2005.0021.

Bieling, C., T. Plieninger, H. Pirker, and C. R. Vogl. 2014. Linkages between landscapes and human well-being: An empirical exploration with short interviews. Ecological Economics 105:19-30. https://doi.org/10.1016/ j.ecolecon.2014.05.013.

Brandt, J. 2003. Multifunctional landscapes - Perspectives for the future. Journal of Environmental Sciences 15:187192.

Burkhard, B., M. Kandziora, Y. Hou, and F. Müller. 2014. Ecosystem Service Potentials, Flows and Demand - Concepts for Spatial Localization, Indication and Quantification. Landscape Online 34:1-32. https://doi.org/10.3097/ LO.201434.

Burkhard, B., A. Müller, F. Müller, V. Grescho, Q. Anh, G. Arida, J. V. Bustamante, H. Van Chien, K. L. Heong, M. Escalada, L. Marquez, D. Thanh Truong, S. Villareal, and J. Settele. 2015. Land cover-based ecosystem service assessment of irrigated rice cropping systems in southeast Asia - An explorative study. Ecosystem Services 14:76-87. https://doi.org/10.1016/j.ecoser.2015.05.005.

Cahuich-Campos, D., L. Huicochea Gómez, and R. Mariaca Méndez. 2014. El huerto familiar, la milpa y el monte maya en las prácticas rituales y ceremoniales de las familias de X-mejía, Hopelchén, Campeche. Relaciones. Estudios de Historia y Sociedad 35:157-184. https://doi.org/10.24901/rehs.v35i140.107.

Campos, J. J., F. Alpizar, B. Louman, and J. A. Parrotta. 2005. An Integrated Approach to Forest Ecosystem Services. Pp. 97-116 in G. Mery, R. Alfaro, M. Kanninen and M. Lovobikov (eds.). Forests in the Global Balance - Changing Paradigms. International Union of Forest Research Organizations, Autria, Viena.

Cristeche, E., and J. Penna. 2008. Métodos de la valoración económica de los servicios ambientales. Estudios Socioeconómicos de la Sustentabilidad de los Sistemas de Producción y Recursos Naturales 3:1-58.

Ellis, E. A., J. A. Romero-Montero, I. U. Hernández-Gómez, L. Porter-Bolland, and P. Ellis. 2017. Private property and Mennonites are major drivers of forest cover loss in central Yucatan Peninsula, Mexico. Land Use Policy 69:474-484. https://doi.org/10.1016/j.landusepol.2017.09.048.

Fagerholm, N., E. Oteros-Rozas, C. M. Raymond, M. Torralba, G. Moreno, and T. Plieninger. 2016. Assessing linkages between ecosystem services, land-use and well-being in an agroforestry landscape using public participation GIS. Applied Geography 74:30-46. https://doi.org/10.1016/j.apgeog.2016.06.007.

Führer, E. 2000. Forest functions, ecosystem stability and management. Forest Ecology and Management 132:29-38. https://doi.org/10.1016/S0378-1127(00)00377-7.

Galhena, D. H., R. Freed, and K. M. Maredia. 2013. Home gardens: a promising approach to enhance household food security and wellbeing. Agriculture and Food Security 2:8. https:/ / doi.org/10.1186/2048-7010-2-8.

Gómez de Silva, J. 2001. Los mayas de Campeche frente a la modernización. Editorial: Gobierno del Estado de Campeche. Campeche, México. Pp. 194.

Granados-Sánchez, D., G. F. López-Ríos, and T. -M. Esteban. 1999. La milpa en la zona maya de Quintana Roo. Revista de Geografía Agrícola 28:57-72.

de Groot, R. S., M. A. Wilson, and R. M. Boumans. 2002. A typology for the classification, description and valuation of ecosystem functions, goods and services. Ecological Economics 41:393-408. https://doi.org/10.1016/S09218009(02)00089-7. 
Haines-Young, R., and M. Potschin. 2010. The links between biodiversity, ecosystem services and human well-being. Pp. 110-138 in Ecosystem ecology: a new synthesis. Cambridge University Press.

Herrera Tapia, F. 2013. Enfoques y políticas de desarrollo rural en México: Una revisión de su construcción institucional. Gestión y Política Pública 22(1):131-159. https://doi.org/10.1017/CBO9780511750458.007.

Horrigan, L., R. S. Lawrence, and P. Walker. 2002. How sustainable agriculture can address the environmental and human health harms of industrial agriculture. Environmental Health Perspectives 110:445-456. https://doi.org/ 10.1289/ehp.02110445.

Hulbert, S. H. 1984. Pseudoreplication and the design of ecological field experiments, Ecological Monographs 54:187211. https://doi.org/10.2307/1942661.

INEGI. 2010. Compendio de información geográfica municipal, Hopelchén, Campeche. Instituto Nacional de Estadística y Geografía. México D.F., México.

KAIROS. 2007. Ordenamiento Ecológico Territorial, Municipio de Hopelchén: Caracterización y Diagnóstico. Secretaría de Medio Ambiente y Recursos Naturales. San Francisco de Campeche, Campeche, México.

Kandziora, M., B. Burkhard, and F. Müller. 2013. Interactions of ecosystem properties, ecosystem integrity and ecosystem service indicators - A theoretical matrix exercise. Ecological Indicators 28:54-78. https:/ / doi.org/10.1016/ j.ecolind.2012.09.006.

Lockwood, M. 1999. Humans Valuing Nature: Synthesizing Insights from Philosophy, Psychology and Economics. Environmental Values 8:381-401. https://doi.org/10.3197/096327199129341888.

Mardero, S., B. Schmook, C. Radel, Z. Christman, D. Lawrence, M. Millones, E. Nickl, J. Rogan, and L. Schneider. 2015. Smallholders' adaptations to droughts and climatic variability in southeastern Mexico. Environmental Hazards 14: 271-288. https://doi.org/10.1080/17477891.2015.1058741.

Martín-López, B., E. Gómez-Baggethun, M. García-Llorente, and C. Montes. 2014. Trade-offs across value-domains in ecosystem services assessment. Ecological Indicators 37:220-228. https://doi.org/10.1016/j.ecolind.2013.03.003.

Millennium Ecosystem Assessment. 2005. Ecosystems and human well-being: current state and trends. Island Press, Washington, D.C.

Morales-Jasso, G. 2016. La apropiación de la naturaleza como recurso. Una mirada reflexiva. Gestión y Ambiente 19: 141-154.

Müller, F., R. de Groot, and L. Willemen. 2010. Ecosystem services at the landscape scale: the need for integrative approaches. Landscape Online 23:1-11.

Opdam, P. 2013. Using Ecosystem Services in Community-Based Landscape Planning: Science is Not Ready to Deliver. Pp. 77-101. Landscape Ecology for Sustainable Environment and Culture. Springer Netherlands, Dordrecht. https: //doi.org/10.1007/978-94-007-6530-6_5.

Paudyal, K., H. Baral, B. Burkhard, S. P. Bhandari, and R. J. Keenan. 2015. Participatory assessment and mapping of ecosystem services in a data-poor region: Case study of community-managed forests in central Nepal. Ecosystem Services 13:81-92. https://doi.org/10.1016/j.ecoser.2015.01.007.

Pérez Izquierdo, O., A. Nazar Beutelspacher, B. Salvatierra Izaba, S. E. Pérez-Gil Romo, L. Rodríguez, M. T. Castillo Burguete, and R. Mariaca Méndez. 2012. Frecuencia del consumo de alimentos industrializados modernos en la dieta habitual de comunidades mayas de Yucatán, México. Estudios Sociales 20:155-184.

Plieninger, T., S. Dijks, E. Oteros-Rozas, and C. Bieling. 2013. Assessing, mapping, and quantifying cultural ecosystem services at community level. Land Use Policy 33:118-129. https://doi.org/10.1016/j.landusepol.2012.12.013.

Plieninger, T., D. van der Horst, C. Schleyer, and C. Bieling. 2014. Sustaining ecosystem services in cultural landscapes. Ecology and Society 19. https:/ / doi.org/10.5751/ES-06159-190259.

Porter-Bolland, L., M. C. Sánchez González, and E. A. Ellis. 2008. La conformación del paisaje y el aprovechamiento de los recursos naturales por las comunidades mayas de La Montaña, Hopelchén, Campeche. Investigaciones Geográficas 66:65-80.

Saenz-Pedroza, I. 2015. La milpa maya y la sucesión secundaria. Desde el Herbario CICY 7:35-37.

Schmook, B., N. van Vliet, C. Radel, M. de J. Manzón-Che, and S. McCandless. 2013. Persistence of Swidden Cultivation in the Face of Globalization: A Case Study from Communities in Calakmul, Mexico. Human Ecology 41:93-107. https: //doi.org/10.1007/s10745-012-9557-5.

Scholte, S. S. K., A. J. A. van Teeffelen, and P. H. Verburg. 2015. Integrating socio-cultural perspectives into ecosystem service valuation: A review of concepts and methods. Ecological Economics 114:67-78. https://doi.org/10.1016/ j.ecolecon.2015.03.007.

Toledo, V. M., N. Barrera-Bassols, E. García-Frapolli, and P. Alarcón-Chaires. 2008. Uso múltiple y biodiversidad entre los mayas yucatecos (México). Interciencia 33:345-352.

Turner, M. G. 1989. Landscape Ecology: The Effect of Pattern on Process. Annual Review of Ecology and Systematics 20:171-197. https://doi.org/10.1146/annurev.es.20.110189.001131.

Uzcanga Pérez, N. G., A. Maya Martínez, and A. de J. Cano González. 2012. Diagnóstico sectorial para la planeación en el estado de Campeche. San Francisco de Campeche, Campeche, México.

Vreese, R. De, M. Leys, C. M. Fontaine, and N. Dendoncker. 2016. Social mapping of perceived ecosystem services supply - The role of social landscape metrics and social hotspots for integrated ecosystem services assessment, landscape planning and management. Ecological Indicators 66:517-533. https://doi.org/10.1016/j.ecolind.2016.01.048.

Wiggering, H., P. Weißhuhn, and B. Burkhard. 2016. Agrosystem services: An additional terminology to better understand ecosystem services delivered by agriculture? Landscape Online 49:1-15. https://doi.org/10.3097/ LO.201649. 